\title{
CMA wants seniors' care on federal agenda
}

$\mathrm{F}$ or the second year running, but bolstered by a new survey, Canada's doctors are calling for a national seniors' health care strategy. "Federal politicians should worry about this if they want to stay federal politicians," Canadian Medical Association President Dr. Louis Hugo Francescutti told CMAJ.

The Canadian Medical Association (CMA) released the survey-based 14th Annual National Report Card on Health Care on the opening day of its annual meeting in Ottawa Aug. 18. In last year's report card, $85 \%$ of the 1000 people (ages 18 and older) surveyed said all levels of government need to cooperate to create a seniors' strategy, citing the looming pressure aging baby boomers will place on the health care system. This year, CMA hired Ipsos Reid to survey 1000 of those baby boomers (ages 45 and older) and 95\% identified the need for a pan-Canadian seniors' care strategy - a percentage that Francescutti called "astonishing."

"That wouldn't have happened 10 years ago." But today, according to the survey, $26 \%$ of baby boomers are caregivers and "they're seeing the level of care that their parents or people they care for are receiving. It's not all bad, but it's bad enough. They don't want that same level of care," says Francescutti.

The survey found that $81 \%$ of older Canadians are concerned about the quality of care they can expect in the future, $78 \%$ worry about access to high-quality home and long-term care and $60 \%$ are concerned that there aren't enough services to help seniors live at home longer.

Levels of care differ substantially in terms of cost. According to the CMA, a one-day stay in hospital costs up to $\$ 1000$, but one day in a longterm care facility costs about $\$ 130$, whereas home care costs $\$ 55$. CMA estimates at least $\$ 2.3$ billion a year could be used more effectively. The

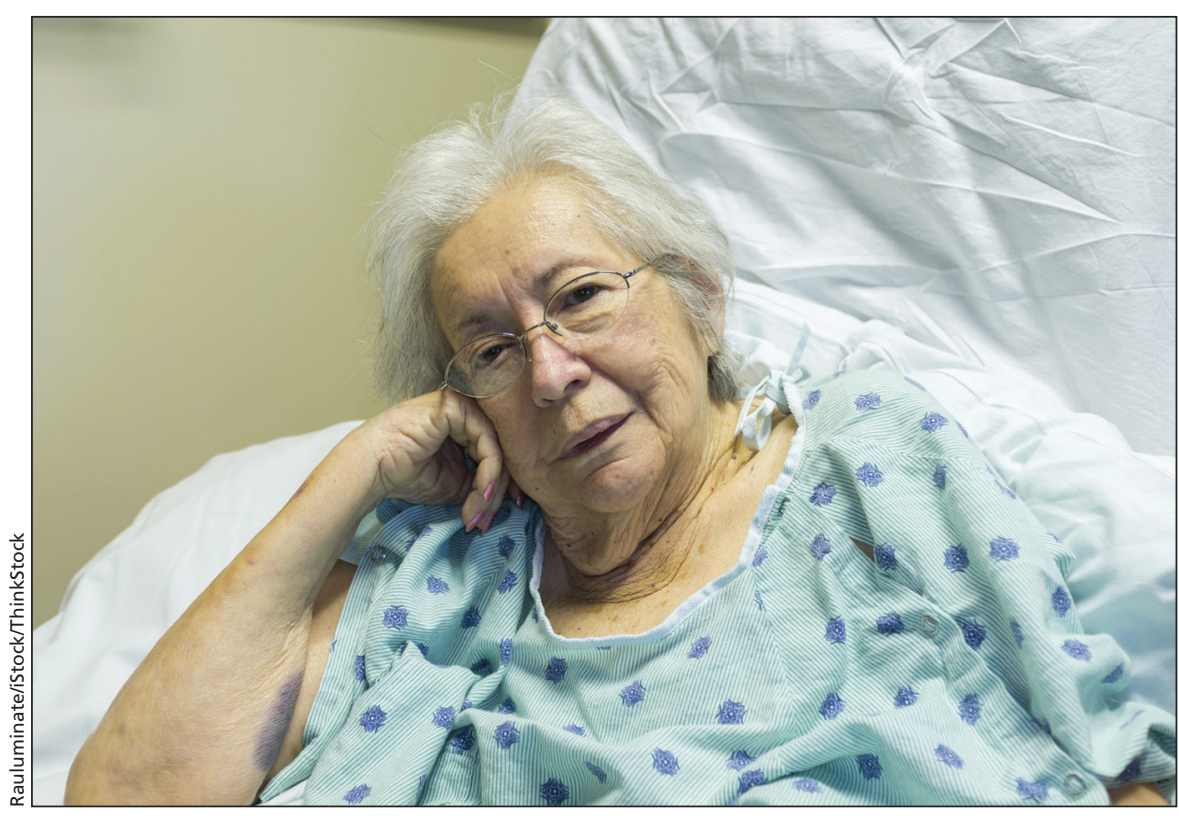

Hospital care, at about $\$ 1000$ a day, is too expensive for patients who could receive home care or live in long-term facilities.

association says a pan-Canadian strategy would allow older people to be cared for at home or in long-term care facilities, reducing hospital bed shortages that are often driving wait times.

More than $90 \%$ of survey respondents agree that finding ways to keep older people living at home for as long as possible and not in hospitals or longterm care facilities, would improve the entire health care system.

"Most care can be delivered in the home environment," says Francescutti.

The CMA survey indicates that seniors' care is a priority for Canadians, says the chair of Canadian Doctors for Medicare. But Dr. Monika Dutt says her organization would like to see a broader federal focus on health care in general, including not only senior's care, but also pharmacare and equitable access. Seniors' care "could be a lead into some of those discussions; that would be beneficial."

Dutt commended the survey for clearly summarizing issues around publicly funded services; $76 \%$ of respondents who had not yet retired said they are concerned about affording uninsured services.

Solutions are needed as the number of seniors continues to grow. In 1971, $8 \%$ of Canada's population was over 65 ; today, it's $15 \%$ and that number is expected to hit $25 \%$ by the time all boomers have turned 65. Meanwhile, health care dollars allocated to seniors increased by only $1 \%$ between 2000 and 2011.

CMA is not alone in its call for a national approach to seniors' care. At a conference in October 2013, provincial health ministers called for a "better continuum of care to support seniors aging at home and in the community," as well as "high-quality supports to avoid hospitalization."

The CMA intends to "push forward" on a national strategy in collaboration with groups such as CARP, an advocacy group for retired persons. A seniors' strategy is "desperately" needed, stated Francescutti. - Barbara Sibbald, CMAJ

CMAJ 2014. DOI:10.1503/cmaj.109-4884 